\section{Medicina chinesa/ acupuntura: apontamentos históricos sobre a colonização de um saber}

\author{
Chinese medicine/ \\ acupuncture: historical \\ notes on the colonization \\ of a body of knowledge
}

\section{Octávio Augusto Contatore}

Doutorando, Faculdade de Ciências Médicas/ Universidade Estadual de Campinas (Unicamp). Campinas - SP - Brasil

oacontatore@yahoo.com.br

\section{Charles Dalcanale Tesser}

Professor, Departamento de Saúde Pública/ Universidade Federal de Santa Catarina.

Florianópolis - SC - Brasil

charles.tesser@ufsc.br

\section{Nelson Filice de Barros}

Livre-docente, Faculdade de Ciências Médicas/Unicamp. Campinas - SP - Brasil

filice@fcm.unicamp.br

Recebido em 13 jan. 2017

Aprovado em 2 jan. 2018.

http://dx.doi.org/10.1590/S0104-59702018000400013
CONTATORE, Octávio Augusto;

TESSER, Charles Dalcanale; BARROS, Nelson Filice de. Medicina chinesa/ acupuntura: apontamentos históricos sobre a colonização de um saber. História, Ciências, Saúde - Manguinhos, Rio de Janeiro, v.25, n.3, jul.-set. 2018, p.841858.

\section{Resumo}

O colonialismo ocidental influenciou, a partir do século XIX, o encontro entre saberes tradicional e moderno, resultando na sobreposição da medicina ocidental como modo privilegiado de conhecimento. Em 1958 oficializou-se, sob o nome de medicina tradicional chinesa, a hibridização entre as medicinas chinesa e ocidental e, por meio do desenvolvimento da pesquisa biomédica sobre a acupuntura, cresceu o distanciamento do saber tradicional. Este ensaio aborda mudanças históricas sofridas pela medicina chinesa/ acupuntura e discute, sob a óptica pós-colonial, os efeitos de sua absorção pela racionalidade médica moderna. Concluiu-se que o cientificismo na medicina chinesa não ampliou seu potencial terapêutico e resultou na perda de sua autoridade epistemológica.

Palavras-chave: medicina tradicional chinesa; acupuntura; biomedicina; colonialismo.

\section{Abstract}

Western colonialism influenced the encounter between traditional and modern knowledge from the nineteenth century onwards, resulting in the overlapping of Western medicine as a privileged form of knowledge. In 1958 the hybridization between Chinese and Western medicines became official under the name of traditional Chinese medicine and, through the development of biomedical research on acupuncture, it distanced itself from traditional knowledge. This essay presents historical changes experienced by Chinese medicine/acupuncture and discusses the effects of its absorption by modern medical reasoning from a postcolonial standpoint. The conclusion was that the scientism of Chinese medicine did not broaden its therapeutic potential and resulted in the loss of its epistemological authority.

Keywords: traditional Chinese medicine; acupuncture; biomedicine; colonialism. 
$\mathrm{E}$ mbora a população da China reconhecesse socialmente a medicina clássica chinesa ${ }^{1}$ como prática de atenção à saúde, a ação colonialista ocidental na China favoreceu, no século XIX e início do século XX, perante a classe política chinesa, a sua gradual desqualificação cultural, teórica e prática. ${ }^{2}$ Em um primeiro momento, o saber médico tradicional não foi alvo das reformas implantadas a partir do final do século XIX, pelo governo Qing, que visava modernizar as instituições e garantir a soberania nacional, com a inserção do ensino de conhecimentos da ciência ocidental.

A medicina chinesa era o único campo que muitos intelectuais consideravam igual, senão superior, à sua contraparte ocidental. Porém, uma epidemia de pneumonia ocorrida em 1910 na Manchúria foi determinante para o governo imperial adotar modelos ocidentais de saúde pública, o que favoreceu a desvalorização na esfera política dos conhecimentos tradicionais de cuidado com a saúde (Lei, 2014).

A partir de 1912, com o governo nacionalista, a medicina chinesa sofreu grande pressão, com sucessivas tentativas de desmonte, o que influenciou seus praticantes a fazer adaptações de sua lógica de cuidado em direção ao pensamento médico ocidental (Andrews, 2014; Lei, 2014). Isso ocorreu com maior ênfase pela sistematização iniciada em 1949-1950 no governo de Mao Tsé Tung, em que se oficializou a hibridização entre o saber médico chinês e a medicina científica ocidental (Unschuld, 1985; Fruehauf, 1999). Sua forma assemelhou-se à objetividade moderna, imprimindo uma descrição materialista/ concreta e racionalista de conceitos/noções autóctones da medicina clássica chinesa sobre o organismo e sua vitalidade, além de descartar noções introspectivas de como cada indivíduo pode autonomamente acessar seu potencial de saúde. Essa influência cresceu após a compreensão científica de alguns dos mecanismos terapêuticos da acupuntura e persiste com as tentativas de adaptar sua prática a um formato que possibilite sua validação pelo modelo de pesquisa biomédica.

O objetivo deste texto é continuar e aprofundar a discussão já existente sobre a mudança na base teórica da medicina chinesa, focando a influência do encontro com a medicina ocidental na sua prática e como isso se reflete na padronização desse conhecimento produzido na China e disseminado no mundo todo. Para tanto, apresentam-se apontamentos históricos do processo de transformação da medicina clássica chinesa para sua vertente moderna, conhecida como medicina tradicional chinesa (MTC).

Foram utilizadas fontes secundárias para o estudo dos processos históricos, a partir das quais se discute como a hibridização com a medicina ocidental resultou na perda da autoridade epistemológica da medicina chinesa (Andrews, 2014) e na interferência negativa na efetividade de sua prática (Jacques, 2005). As modificações sofridas descaracterizaram sua forma original de compreensão do processo saúde-doença-cuidado, aproximando-o da lógica biomédica, o que resultou em tentativas vãs de validá-la com métodos inapropriados (Souza, Luz, 2011; Contatore et al., 2015) e na falácia do discurso de integração e complementaridade entre medicinas, quando há, continuamente, a sobreposição do saber médico ocidental (Gale, 2014). 


\section{Apontamentos sobre o contexto político}

A medicina ocidental foi introduzida no território chinês no início do século XIX, por missionários europeus e norte-americanos que tinham como missão catequizar a população local, e, por quase cem anos, ela foi exclusivamente representada por eles. Em um primeiro momento, o governo imperial e grande parte da população não mostraram interesse em absorver os novos modelos de medicina e de religião apresentados pelos missionários. Já no final do século XIX e início do XX, com o enfraquecimento do governo imperial e a ascensão do poderio estrangeiro na China, inclusive sob influência do Japão, que já havia absorvido e introduzido em seu território alguns valores ocidentais, a população chinesa interessou-se pela nova medicina não por acreditar em sua maior efetividade terapêutica, mas por se identificar com o discurso da modernidade (Andrews, 2014) - com poucas exceções, como foi o caso de Wang Qingren, que criticou e reavaliou o conhecimento anatômico médico clássico (Lei, 2014).

Ocidentais que visitaram a China no século XIX e conheceram sua medicina exprimiram opiniões de repúdio e de apreço. Um missionário norte-americano desse período avaliou que a medicina chinesa era mais baseada em misticismo do que em evidências científicas e que a superstição havia impedido os médicos chineses de adquirir conhecimentos em anatomia e química. Taxou a pulsologia chinesa como um método de diagnóstico em que só os charlatões fingiriam confiar totalmente (Shelton, 2013). Já o cônsul da França na China, Dabry de Thiersant, ao tomar contato com a medicina chinesa, interessou-se em aprofundar seus conhecimentos. Em 1863, publicou o livro A medicina entre os chineses, em que apresentava cuidadosamente a técnica da acupuntura e os princípios filosóficos da medicina chinesa (Fróio, 2006). Dabry de Thiersant (1863) buscou preencher a lacuna de conhecimento ocidental sobre as obras originais da medicina chinesa, que eram de pouco acesso ao público europeu, traduzindo os princípios técnicos para utilização no contexto da medicina francesa, sem julgar o mérito ou superioridades/inferioridades das duas medicinas.

Como afirma Granet (1997), a China perturba e fascina o Ocidente ao mostrar a possibilidade de existir um pensamento diferente do nosso e dotado de alta capacidade civilizatória. Entretanto, a China, como todo o Oriente, sofreu os impactos causados pela colonização ocidental, refletidos no abandono de elementos tradicionais de sua cultura, na absorção de novos valores e maneiras de compreender o mundo.

Para fazer uma crítica adequada ao processo colonizador ocidental é preciso considerar que o etnocentrismo não é uma característica exclusiva da Europa e que as sociedades humanas o exibem a sua maneira (Goody, 2008). A sociedade chinesa, entre elas, serve como exemplo. A China dos séculos XVIII e XIX estava tão centrada em seus costumes e valores, que considerava os ingleses um povo bárbaro devedor de tributos ao imperador e dependente de direitos de comércio que esse podia lhe dar (Lanna, 2001). Considerando tais aspectos, e não descartando que a própria crítica pós-colonial oculta um viés eurocêntrico, não é possível deixar de levar em conta a força colonizadora do Ocidente e a assimilação e desqualificação dos saberes do Oriente; especialmente no que concerne ao discurso que conclama a superioridade europeia em relação à barbárie das sociedades africanas e das civilizações da Ásia (Goody, 2008). 
Interessante observar que no passado e, de certa forma, ainda na atualidade há a crença de o Ocidente ser o exemplo de civilização. Juntamente com sua reivindicação de ter desenvolvido as mais importantes ideias que tiraram o mundo não europeu de seu passado bárbaro, tais como a democracia, o capitalismo mercantil, a liberdade e o individualismo. Isso porque essas ideias já estavam presentes em outras culturas e foram assimiladas pelos gregos ou durante a colonização europeia (Goody, 2008).

Diferenças na forma como cada povo desenvolveu seus conhecimentos certamente existem. No entanto, uma comparação superficial, desde a Modernidade, entre Ocidente e Oriente tem favorecido o primeiro, especialmente quando a avaliação é organizada a partir daquele que a examina (Goody, 2008). Os orientalistas, por exemplo, como afirma Said (1990), no seu papel de pesquisadores das culturas orientais e "detentores" do saber dos povos por eles estudados, foram célebres representantes do etnocentrismo europeu. Esse regime de saber refletiu na autodesqualificação e subordinação dos povos colonizados, sendo que os estudos pós-coloniais têm demonstrado as estratégias de convencimento do colonizador na divulgação dos méritos de seu conhecimento e de seu modo de produção de saber (Hall, 2003; Fanon, 2008; Santos, 2008).

Nesse contexto, a biomedicina, como a representante ocidental nas questões de saúde por meio de seu aporte moderno/científico, tem controlado a narrativa sobre saúde/doença desde o início do século XX, independente da existência de outras formas de medicina. Notadamente nos contextos institucionais e com o argumento de garantir a qualidade dos cuidados, a biomedicina tem regulado as práticas profissionais e os termos em que ocorre o encontro entre médico e paciente, além de acompanhar as qualificações e intervenções dos cuidadores (Andrews, 2014).

As colonizações europeia e posteriormente norte-americana, com seu poder bélico e econômico, como também a guerra com o Japão, foram determinantes para induzir o governo chinês à adoção de políticas restritivas culturais que influenciaram o desprestígio dos saberes tradicionais daquele povo (Palmeira, 1990; Luesink, 2009; Andrews, 2014). O empreendimento bélico/econômico mais significativo constituiu nas Guerras do Ópio (1839-1842, 1856-1860), que perpetuaram um século de submissão chinesa ao Ocidente. Os ingleses, para equilibrar a balança comercial, que, no século XIX, pendia para a China, introduziram, pela força de seus canhões, o ópio naquele território, criando um lucrativo mercado consumidor de um produto proibido na Inglaterra. Quando o governo chinês tentou impedir seu consumo, a Inglaterra exerceu sua superioridade militar, matando milhares de chineses, saqueando suas riquezas (expostas ainda hoje no Museu Britânico), impondo tratados desiguais e incorporando para si trechos do território chinês, o que forçou a China não só a permitir a importação do ópio, mas a consumir outros produtos da crescente indústria inglesa, inclusive os relacionados à medicina. Percebendo a fragilidade militar chinesa, a França, a Alemanha, os EUA e o Japão, posteriormente, também se utilizaram da situação para perpetrar algum domínio militar e/ou econômico sobre os chineses (Lanna, 2001; Arruda, 2006; Coggiola, 2016).

Em função das derrotas da contraposição à entrada do poder estrangeiro no país, no início do século XX, ficava claro para o povo chinês que havia pouca chance de o governo imperial Qing manter a China independente como Estado. Sob a necessidade premente 
de mudança para sobreviver ao poderio de nações estrangeiras, o governo imperial, de 1901 a 1911, e o novo governo, a partir de 1912, após a Revolução Nacionalista, realizaram reformas estruturais e modernizações que interferiram no imaginário da população quanto aos dotes da medicina ocidental e limitações da medicina chinesa (Andrews, 2014; Lei, 2014). O envolvimento com as potências estrangeiras levou à subordinação econômica da China, em termos estabelecidos pelos ocidentais. "Até hoje, os historiadores chineses do continente referem-se ao período entre 1895 e a fundação da República Popular da China em 1949 como guochi - [o período de] humilhação nacional" (Andrews, 2014, p.17). ${ }^{3}$

A derrocada do valor simbólico da medicina clássica chinesa foi gradual, mas alguns acontecimentos de caráter cultural e/ou político ocorridos na China nos séculos XIX e XX foram significativos para o desfecho que culminou na sua hibridização com a medicina ocidental.

Em meados do século XIX, aquilo que para o etnocentrismo chinês era algo único, a medicina (yixue), passou na linguagem da época a ser subdividido em dois termos que diferenciavam a medicina ocidental (xiyi) da medicina chinesa (zhongyi) (Fruehauf, 1999).

Em 1907, na conferência intitulada "A century of medical mission in China", James Maxwell, secretário executivo da Associação Médica Chinesa, concluiu que pouco havia sido feito naquele país pela ação médica missionária para a implantação de uma medicina preventiva. No entanto, ele argumentou que, independente disso, houve um avanço extremamente necessário para exercer influência intelectual, social e política e alcançar os principais homens do império chinês. Os novos recursos técnicos oferecidos pela medicina ocidental, nas áreas de oftalmologia e cirurgia, foram decisivos para impressionar aos signatários que tiveram acesso a tais expedientes e estabelecer um valor social à nova medicina, além de imprimir a ideia de que o moderno era superior ao tradicional (Lei, 2014).

Em 1910, uma epidemia de pneumonia ocorrida na Manchúria foi o primeiro acontecimento, sob o controle do governo chinês, de saúde pública moderna. Esse evento destacou politicamente a importância estratégica da medicina ocidental para a construção do Estado chinês frente as potências estrangeiras. O uso da medicina ocidental ajudou o governo imperial a controlar a doença, como também demonstrou a soberania nacional, evitando o uso de serviços sanitários russos e japoneses liderados por militares. Contudo, também foi decisivo para mostrar limitações da medicina chinesa no tratamento de doenças contagiosas, especialmente na prevenção de novos casos e na contenção daqueles detectados. Em alguns tratamentos de pacientes infectados, a medicina chinesa mostrou maior efetividade terapêutica, mas não o suficiente para valorizá-la diante da medicina ocidental, que se sobressaiu na forma de obter o diagnóstico do agente infeccioso e na prevenção da propagação da doença, mas não no seu tratamento (Andrews, 2014; Lei, 2014).

Em 1916, a Fundação Rockefeller financiou a construção de um hospital, com a proposta de servir como um modelo de elite para instilar "o espírito científico" nas mentes chinesas (Lei, 2014, p.2). Sob essa influência, uma agenda de reforma do conhecimento tradicional, utilizando-se como critério a ciência moderna, foi iniciada no governo nacionalista. Ocorreram vários debates a respeito do que deveria constar nos postulados teóricos da medicina chinesa e decidiu-se pelo banimento de tudo que fosse considerado supersticioso (Andrew, 2014). 
Em 1929, na primeira convenção chinesa de saúde pública, representada em sua maioria por praticantes da medicina ocidental, decidiu-se unanimemente por abolir a medicina chinesa. O texto redigido em 1929 continha três propostas: (1) restringir severamente a prática da medicina chinesa; (2) proibir propagandas da medicina chinesa; (3) proibir o estabelecimento de escolas de medicina chinesa. Mesmo que as propostas não tenham sido implementadas, ainda assim causaram um grande impacto na medicina chinesa nas décadas de 1930 e 1940 (Fruehauf, 1999). Essa ação não foi levada adiante, em função da resistência organizada por uma influente coalizão de médicos tradicionais. A preservação da medicina chinesa também foi defendida por governadores regionais, que argumentaram ser impossível para a maior parte da população receber assistência dos escassos recursos médicos ocidentais, especialmente fora dos grandes centros urbanos (Lei, 2014). Entre os praticantes da medicina chinesa cresceu a organização de grupos que buscaram preservar sua prática e seu estudo, porém com divergências conceituais. Os membros mais velhos dos grupos mantinham uma postura conservadora e queriam preservar seus preceitos, já os mais novos, identificados com a biomedicina, propunham seu cientificismo. No jogo de forças, os mais velhos foram empurrados para a periferia (Lei, 2014).

Consequentemente, chineses formados em medicina ocidental continuaram acreditando na importância de abolir a medicina chinesa. Foi o caso de C.C. Chen, que em 1980 ainda acreditava que a substituição da medicina local pela medicina científica, apesar de ter sido atrasada por tantos anos, era mera questão de tempo. Porém, a disputa ideológica, ocorrida em 1929, entre as duas medicinas transformou-se em um confronto epistemológico, em que a medicina chinesa foi pressionada pelos discursos modernistas a demarcar uma divisão entre o moderno e o pré-moderno. Esse evento foi determinante para a indução de reformas na sua estrutura, intensificadas a partir de 1950, que transformaram radicalmente as teorias, as práticas e a pedagogia tradicionais (Lei, 2014).

Mao Tsé Tung, por exemplo, em 1942 escreveu que velhos médicos, artistas de circo, vendedores de óleo de serpente e vendedores ambulantes eram todos iguais. Após a Revolução Cultural, seus textos foram usados como estímulo para a perseguição de representantes da cultura médica tradicional pela Guarda Vermelha (Fruehauf, 1999).

Ambiguamente, fatores políticos após a Revolução Cultural (1949) mantiveram e reeditaram a medicina chinesa concomitante a ações que visavam restringi-la. Para abordar tais mudanças baseamo-nos no trabalho de Heiner Fruehauf, pós-graduado pela Universidade Chengdu de Medicina Tradicional Chinesa (MTC), que, da mesma forma que o grupo composto por Cui Yueli (ministro da Saúde), Fang Yaozhong (Academia Chinesa de Pesquisa de MTC), Deng Tietao (Universidade Guangzhou de MTC), Fu Jinghua (Academia Chinesa de Pesquisa de MTC), Li Zhichong (Associação Chinesa de MTC) e Zhu Guoben (ministro nacional de MTC) tem criticado as transformações sofridas pela medicina chinesa na sua hibridização com a medicina ocidental (Fruehauf, 1999). A relevância dos dados trazidos por Fruehauf (1999) é de divulgar fora da China a publicação feita em 1997 intitulada Zhongyi Chensi Lu (Refletindo sobre as questões centrais da medicina chinesa). Esses autores explicitam discussões não hegemônicas que criticam o discurso reducionista do governo chinês, o qual desqualificou a medicina clássica e permanece afirmando só haver 
progressos no encontro entre as medicinas oriental e ocidental. Assim sendo, destacam-se alguns apontamentos a esse respeito:

- O modelo socialista concebido por Mao Tsé Tung incorporava os atributos regionais dos países do Terceiro Mundo, e a medicina chinesa se enquadrava nesse esquema, pois, para ele, era autossuficiente, do povo, nativa e patriótica. Outro ponto relevante foi a necessidade econômica de diminuir a dependência de bens e conhecimentos soviéticos modernos, especialmente na área de equipamentos médicos e farmacêuticos.

- Em 1956, o primeiro-ministro Zhou Enlai assinou os documentos que autorizaram o estabelecimento imediato de quatro colégios para o ensino da medicina chinesa. O primeiro grupo de diretores era formado por médicos tradicionais que receberam sua formação pelo modelo de discipulado pré-institucional. Eles ficaram conhecidos como os cinco anciãos.

- Em 1958, Mao Tsé Tung publicou um texto que desenvolvia o conceito de integração entre a medicina chinesa e a ocidental (zhong xi yijiehe), oficializando o estabelecimento da MTC. Para Mao, a MTC era "um sistema médico que restringe a 'selvageria' e os 'elementos feudais' da arte tradicional, tirando-a das mãos de seus detentores de linhagem e atribuindo-a ao controle da ciência moderna, uma das ferramentas mais confiáveis da ideologia marxista-materialista" (Fruehauf, 1999, p.4). Na sequência, ele anunciou a realização de uma pesquisa nacional com o intuito de selecionar dois mil chineses formados em medicina ocidental para ajudar na evolução da medicina chinesa. Só 10\% dos médicos se qualificaram para a função, e a sua grande dificuldade foi aprender a medicina chinesa, memorizar seus detalhes e, dada sua formação médica ocidental, lidar com o que era considerado o produto de superstições de um sistema feudal. Nos anos de 1980 e 1990, a maioria dos administradores públicos da MTC pertencia a esse grupo.

- Em 1966, Mao Tsé Tung deu início à Grande Revolução Cultural, que, por dez anos, buscou erradicar todo vestígio de influência tradicional. Todos os antigos mestres da medicina chinesa, incluindo os cinco anciãos, foram expostos a críticas e humilhações, em alguns casos exibidos publicamente. Muitos médicos tradicionais, para evitar as perseguições, queimaram seus livros, e outros morreram em consequência dos abusos sofridos, o que levou à perda de grande parte do legado físico da medicina chinesa.

- Entre 1966 e 1971 iniciou-se a formação dos chamados "médicos de pés descalços", para atender a população rural. Foi criado um programa de treinamento de três anos, com elementos básicos de medicina ocidental e chinesa, que poderia ser cursado por alunos com instrução inferior ao ensino médio.

- Entre os anos de 1980 e 1990, em nome do progresso, houve na formação da MTC a introdução de "metodologia superior", "padrões científicos", "axiomas de pesquisa" e estabeleceu-se o conceito de que a "medicina chinesa melhoraria pela metodologia de investigação". Essas medidas deram "caráter científico" a determinados aspectos do conhecimento da medicina chinesa e negaram a outros a mesma validação e, consequentemente, o direito de ser preservados e transmitidos (Fruehauf, 1999, p.6).

- De 1994 a 1995, o Ministério da Saúde chinês, para efeito de novas patentes, publicou uma série de diretrizes oficiais destinadas a padronizar a pesquisa e o estudo de medicamentos tradicionais, utilizando como critério os padrões farmacêuticos ocidentais. Mais especificamente, substituiu o diagnóstico tradicional diferencial (bianzheng) pelo 
diagnóstico alopático (bianbing). Uma nova classe de estudantes em medicina chinesa não pôde mais diagnosticar pelo método tradicional e foi formada no sistema alopático de terminologia médica e de diagnóstico.

Observa-se, portanto, que a política atuou de forma relevante na realização da hibridização entre a medicina chinesa e a ocidental, sob a égide da supervalorização da medicina ocidental em detrimento do saber clássico.

\section{A medicina chinesa depois da influência ocidental}

A medicina clássica chinesa, que encontrou a ocidental no século XIX, já havia passado por um processo de transformação conceitual, com a separação de aspectos místicos/religiosos da prática terapêutica (Unschuld, 1985), similarmente ao que ocorreu durante o desenvolvimento da clínica médica no Ocidente durante os séculos XVII e XVIII (Foucault, 1977). No entanto, as práticas ancestrais da medicina chinesa não foram totalmente descartadas ou banidas, mas continuaram existindo em suas múltiplas formas de cuidado.

$\mathrm{Na}$ China, as "concepções criadas em diferentes momentos históricos convivem sem substituição de um antigo conceito por um novo" (Moraes, 2007, p.18). A lógica contida no pensamento clássico chinês, derivada da observação das relações harmônicas do universo, da contemplação dos ciclos da natureza, das funções do organismo e de suas inter-relações, desenvolveu um raciocínio sintético e dinâmico que se diferencia do raciocínio ocidental, analítico e estático, baseado na causalidade linear (relações de causa/efeito) e na observação de objetos ou fenômenos relativamente isolados de seu contexto (Jullien, 2001).

O pensamento clássico chinês não opõe sujeito ao objeto, mas estabelece as ligações entre ambos. Tem um sentimento íntimo da unidade do mundo. Recusa-se a distinguir o lógico e o real. Estabelece outras relações entre os números, o espaço e o tempo. Dominados pelas ideias de ordem, totalidade e ritmo, os chineses criaram categorias diferentes daquelas que dirigiram a formação do pensamento ocidental moderno (Granet, 1997). A eficácia da ação humana encontra-se na harmonia com o processo natural, em uma relação de arranjo e organização hierarquizada em múltiplos sistemas, que pode ser chamada de ação do ser humano no seu ecossistema, mas que responde a uma identidade estrutural reveladora da unidade ordenada do universo (Sampaio, 2002).

$\mathrm{Na}$ antiguidade chinesa, as funções sacerdotal e terapêutica eram completamente fundidas e, desde as primeiras dinastias registradas (Shang, 1751-1112 a.C.) até a metade da dinastia Zhōu (1112-249 a.C.), havia uma mistura de atividades oraculares, de adivinhação e de culto aos ancestrais nas práticas terapêuticas. A mudança nesse cenário durou aproximadamente de cinco a sete séculos, desde o surgimento das primeiras concepções distintas até sua consolidação. Somente no período médio da dinastia Zhōu, próximo ao ano 500 a.C., evidenciou-se a diferenciação entre as funções do sacerdote e do terapeuta, bem como o uso organizado de substâncias medicinais para a cura de enfermidades. Há também referências sobre a acupuntura, assim como registros de diagnose pelas noções de calor e frio, escuridão ou claridade, relacionadas à teoria yīn-yáng (Unschuld, 1985). 
Nesse período viveram os chamados "filósofos" ou sábios, que influenciaram mudanças nas crenças e valores sociais, incluindo a medicina. Kǒng Fū (Confúcio) influenciou a medicina com a ênfase na noção de moderação e relacionou que o desrespeito à higiene, à moderação alimentar, à regularidade no sono e no trabalho poderiam provocar doenças (Unschuld, 1985; Sampaio, 2002). Já Lăo Zǐ, nome (lendário) relacionado ao daoismo, ${ }^{4}$ esteve vinculado com a compilação do Dào Dé Jīng, onde estão explicitadas concepções como dào, dé, wúwéi e yīn-yáng, que fundamentam as práticas curativas clássicas chinesas. Finalmente na dinastia Hàn (206 a.C.-220 d.C.), as concepções que vinham se acumulando foram sistematizadas e compiladas em dois cânones fundamentais, Huáng Dì Nei Jing, o Livro do imperador Amarelo, e o Nan Jing, o Clássico das dificuldades (Unschuld, 1985; Sampaio, 2002). Nesses cânones foram integradas todas as concepções prévias num modelo coerente, em que as teorias dos canais de energia (jīng mài) e dos órgãos e vísceras (zàng fŭ) constituem o núcleo da descrição dos componentes e do funcionamento dos seres humanos. Também a teoria dos fatores patogênicos passa a ser a principal forma de explicar o adoecimento, substituindo explicações anteriores. Nesse modelo, os fatores patogênicos foram divididos em externos (fatores climáticos) e internos (emoções), ambos relacionados aos zàng fú (órgãos e vísceras); e nem externos nem internos (hábitos alimentares e comportamentais, acidentes e ataques de animais) (Unschuld, 1985). Para avaliar-se o estado dinâmico de equilíbrio do organismo, na realização do processo diagnóstico e definição do princípio de tratamento e da terapia, utilizava-se a noção de mutação cíclica dos sopros yīn e yáng, importante fundamento da cosmologia daoista (Coutinho, Dulcetti, 2015). Outro clássico influente nas definições das causas do adoecimento, diagnóstico e modo de tratamento foi o livro Shang-Han Lun (Tratado do frio nocivo) (Wong, 1988).

A gênese das enfermidades era pensada a partir da interação e capacidade adaptativa do ser individual com a natureza, sendo essa interligação a base das concepções cosmológicas do modelo que tem o ser humano e o cosmo como um conjunto integrado por meio de uma força vital única denominada qi. A concepção de qi se tornou um dos principais fundamentos da medicina chinesa, assumindo a função de uma força conectiva de todos os sistemas, internos e externos (Unschuld, 1985; Tesser, 2010). E a distinção de onde está a insuficiência ou o excesso do qi faz parte do diagnóstico em medicina chinesa (Coutinho, Dulcetti, 2015).

Pela transmissão oral do conhecimento clássico da medicina chinesa, o qi, na sua forma mais sutil, está presente no organismo desde o momento da concepção e tem como fontes a natureza (o cosmo) e a vitalidade dos genitores. Durante a gestação e nos primeiros meses de vida a criança continua a ser suprida pela natureza. Já a vitalidade recebida pelos alimentos era considerada de menor valor, necessária à vida, mas sem a potencialidade do qi original (Tesser, 2010).

A medicina clássica chinesa desenvolveu, a seu modo, noções básicas de saúde. Em um texto do século IV a.C. encontrou-se pela primeira vez a palavra weìshēng: higiene, composta de dois ideogramas weì (proteção) e shēng (viver). Em inscrições do século XIII a.C. foram encontrados os termos doenças, sintomas, bem como noções de higiene diária e de combate a parasitas (Sampaio, 2002).

Essas concepções, associadas entre si pelos chineses, perduraram estáveis até o início do século XX e são o substrato do que foi chamado de medicina clássica chinesa, 
fundamentando-se historicamente como a medicina tradicional daquele país (Barsted, 2003; Souza, 2008).

Convém salientar que essa racionalidade médica (Luz, 2012) desenvolveu um sistema terapêutico fundamentado em cinco pilares: (1) terapia medicamentosa com substâncias vegetais, animais e minerais; (2) acupuntura e moxabustão; (3) dietética; (4) massagens; (5) práticas de autocuidado com treinamentos de energia (qigong) e formas de meditação com objetivo terapêutico. Esses cinco pilares operavam de forma integrada e contínua, desde o tratamento de enfermidades até a promoção da saúde (yangsheng); seu uso variava de acordo com os padrões clínicos do paciente e as condições geográficas locais, porém, operavam como um sistema único, sendo impossível reduzir a medicina chinesa à prática da acupuntura (Tesser, 2010).

Um dos representantes no Brasil da tradição daoista, Liu Pai Lin (Hemsi, 2015; Bizerril Neto, 2005, 2007), concebia o saber clássico como um tripé indissociável, constituído das "práticas meditativas"- tao in (dao in), de "movimento" - tai chi chuan (dai ji) e tchikun (qiqong) e de "medicina" (fitoterapia chinesa, acupuntura, moxabustão, massagem - tui na). O terapeuta aprenderia e utilizaria essas práticas para o desenvolvimento do autocuidado, de si e da pessoa por ele atendida.

Para Liu Pai Lin, havia três tipos de médicos. O de nível mais alto equilibra em si mesmo o fluxo da vitalidade para prevenir adoecimentos e é capaz de ensinar ao outro como fazêlo; o de nível médio avalia os sintomas, compreende a alteração do fluxo vital e ajuda no seu restabelecimento; e, por último, está aquele que não compreende as etapas anteriores e trata somente da doença já instalada, o que dificulta a recuperação do paciente (Hemsi, 2015; Tesser, 2010). Talvez a característica mais marcante da medicina clássica chinesa seja a sua ênfase preventiva e especialmente a forma como ela foi desenvolvida, pela interrelação entre autoconhecimento e saúde e, especialmente, pelo compartilhamento do saber.

Contudo, conforme os apontamentos históricos brevemente apresentados, a racionalidade médica hoje conhecida como medicina tradicional chinesa, promovida pela República Popular da China, refere-se a um estilo específico oficializado pelo Estado, a qual se estrutura seletivamente sobre a base e as noções da medicina clássica chinesa (Palmeira, 1990; Moraes, 2007). Sua prática terapêutica a aproxima da padronização do cuidado nos moldes biomédicos, com foco no diagnóstico e tratamento da doença e, com menor ênfase, na sua base conceitual, voltada para um cuidado singularizado. Com isso, esse processo enfraqueceu uma de suas características clássicas, que é tratar o doente compreendendo a complexidade do processo individual do adoecimento, contextualizando-o ambientalmente e visando potencializar a saúde para além de relacionar diretamente sintomas a patologias (Tesser, 2010; Coutinho, Dulcetti, 2015).

A nova medicina chinesa apresenta fortes traços positivistas, como uma implícita preocupação com a lógica e com critérios de cientificidade ocidentais. Na sua constituição houve a exclusão de preceitos filosóficos que fundamentavam a medicina clássica e a negação de noções básicas, como ocorreu com os conceitos de shen (espírito) e yang sheng (nutrir a vitalidade), que foram associados a crenças supersticiosas ou descartados pela sua subjetividade (Ferreira, Luz, 2007; Souza, 2008). Também não se deu a devida importância à teoria yīn e yáng e sua fundamental contribuição para a compreensão do processo de 
adoecimento do organismo (Coutinho, Dulcetti, 2015). Além disso, há na MTC uma tendência à materialização da acupuntura, como, por exemplo, atribuir sua ação ao sistema nervoso e denominar certas categorias abstratas da medicina chinesa de "substâncias vitais" ou "fundamentais" (Barsted, 2003; Fróio, 2006). Ou, numa leitura anatômica ocidental, traduzir como órgãos e vísceras os zang fu, desconsiderando que na medicina clássica eles são entidades relacionadas à energia vital, centros que armazenam essência e produzem qi no organismo (Moraes, 2007). Essas traduções/interpretações favorecem o distanciamento do modo clássico de compreender, diagnosticar e atuar nos processos de saúde e doença.

Outro ponto significativo na diferença entre a medicina clássica e a MTC pode ser encontrado na sua fundamentação epistemológica (Tesser, 2013). Enquanto a nova medicina vai aplicar um racionalismo um tanto ocidentalizado aos saberes tradicionais, considerandoos "teorias", a tradição clássica compreende que o fundamento das noções básicas e a sua percepção podem ser obtidos pela prática de técnicas de cultivo do qi.

A MTC descreve a vitalidade do organismo ( $q$ i) com base nos processos biológicos característicos do pensamento médico ocidental. Assim, as fontes da vitalidade seriam os genitores, os alimentos e o ar, descartando a existência de qualquer outra fonte que fuja à materialidade e ao entendimento racional. Já a tradição clássica tem como fundamento básico também a existência de uma energia vital sutil, adquirida diretamente da natureza desde o momento da concepção. Essa vitalidade pode ser reabsorvida e autoestimulada e, em uma acepção cosmológica, é o produto da inter-relação entre o céu, a terra e o ser humano (Sampaio, 2002; Tesser, 2010).

Na transmissão oral dos mestres daoistas e em textos clássicos chineses há a noção de que a percepção do tchi (qi) e o aumento do seu potencial no organismo podem ser obtidos pela prática de técnicas do seu cultivo, como o tao in (dao in) e o tchikun (qigong) (Hemsi, 2015; Bizerril Neto, 2005, 2007; Souza, 2008; Tesser, 2010). Os métodos e práticas que permitem a "visão reverberativa da cena interna" ou "introexploração", conforme Jianping (2001, p.73-77), ou a percepção da energia vital, tchi (qi), conforme Liu Pai Lin (Hemsi, 2015; Bizerril Neto, 2005, 2007), exigem aprendizado e prática de técnicas meditativas e "energéticas" tradicionais. "Apenas aqueles que têm adquirido certo treinamento ... (mestres de qigong e meditadores) podem ver introspectivamente ... observar e reconhecer a cena interna" (Jianping, 2001, p.74).

O conhecimento daoista, entendendo-o como base da medicina clássica chinesa, é um conhecimento adquirido por uma prática pessoal, em que a serenidade e a introspecção são fundamentais para cada um, autonomamente, equilibrar sua vitalidade e desenvolver consciência corporal. Faz parte essencial da aprendizagem dos terapeutas em medicina clássica chinesa conhecer minimamente sua própria vitalidade e ser capaz de cuidar de si mesmo para, então, cuidar da vitalidade de outras pessoas. A expertise terapêutica não se dá somente pelo aprendizado teórico, vem, também, do entendimento pessoal dos fatores internos ou externos que interferem positiva ou negativamente no equilíbrio energético, podendo ser: climáticos, alimentares, emocionais, do cansaço, da falta ou do excesso de exercícios físicos ou qualquer outro fator que possa ser autorreferido. Proporcionar ao outro o conhecimento necessário para o desenvolvimento de seu autocuidado também faz parte da prática terapêutica e isso só é possível com o acolhimento à subjetividade e a atenção ao 
mundo social do sujeito atendido. As ações de cuidado não se resumem à aplicação técnica, muito menos padronizada. Para tanto, são ofertadas informações práticas para o exercício do cuidado pessoal, contribuindo para o desenvolvimento da percepção e do conhecimento das próprias fragilidades e potencialidades (Hemsi, 2015; Tesser, 2010, 2013).

Por sua vez, a formação médica ocidental e as ações de seus praticantes estão mais para um cientista que estuda a doença do que para um terapeuta focado no sujeito doente. Com isso, priorizam-se os estudos laboratoriais de natureza analítica e desenvolve-se um modelo de cuidado prescritivo (Luz, 2014). O abandono do diagnóstico diferencial clássico e a utilização dos métodos ocidentais focados no processo patológico, atualmente em prática na formação em MTC, além de contribuir para um tratamento despersonalizado, têm reduzido ao mínimo a ação dos recursos da medicina clássica (Palmeira, 1990). Na pesquisa em fitoterapia chinesa pelo método farmacêutico ocidental, ao descartar os métodos tradicionais de compreensão das substâncias de fórmulas tradicionalmente em uso e analisar apenas quimicamente o princípio ativo, relacionando-o ao tratamento da patologia, foi reduzida a ação de medicamentos a uma ínfima porcentagem de problemas de saúde por ele tratado. A fórmula clássica si nisan, por exemplo, seria usada apenas para colecistite, 10\% do seu potencial de uso comparado ao método tradicional (Fruehauf, 1999).

Em comparação, o diagnóstico diferencial da medicina clássica chinesa procura cuidar do processo de adoecimento pela atenção meticulosa da descrição dos sintomas, pela análise dos sinais que podem estar presentes no pulso, na língua, na coloração do rosto e das mãos, no tom de voz, no movimento corporal ou apalpando regiões específicas do corpo para avaliar sua textura e/ou temperatura (Moraes, 2007; Tesser, 2010). O conjunto desses sinais é codificado por parâmetros extremamente subjetivos para a racionalidade médica ocidental (Moraes, 2007), pois representam alterações no fluxo da vitalidade, do yīn (hipofuncionamento) e do yáng (hiperfuncionamento) (Wong, 1988), próprias do organismo de cada pessoa. O tratamento visa redirecionar o fluxo da vitalidade tonificando a deficiência, sedando o excesso ou dispersando a estagnação do tchi (qi) (Tesser, 2010). Como exemplo, pessoas que procuram o tratamento com dores no estômago podem referir terem sido diagnosticadas pela biomedicina com gastrite, no entanto, para a medicina chinesa, os caminhos que levaram ao desenvolvimento daquela condição não foram os mesmos, não só do ponto de vista histórico de cada um, mas especialmente das características próprias de cada organismo e sua reação aos estímulos vividos, o que conduz a tratamentos variados, para o que aparentemente seria um mesmo problema.

Além da transformação contemporânea na medicina clássica na China, outra mudança mais recente e importante de ser destacada vem ocorrendo no Ocidente. Após a década de 1970, fruto da atividade científica dirigida especificamente à acupuntura, outra vertente dessa técnica apareceu, com desenvolvimento de teorias e explicações científicas para sua ação. Essa nova teoria, denominada acupuntura neurofuncional, cresceu rapidamente, permitindo o aparecimento de um movimento entre os acupunturistas formados na medicina ocidental na direção da rejeição ou afastamento dos saberes e técnicas tradicionais (Palmeira, 1990; Pai, 2005; Jacques, 2005; Moraes, 2007).

No entanto, os estudos científicos que comprovaram alterações bioquímicas desencadeadas pela aplicação de agulhas em pontos específicos no corpo, apesar de ser 
exaltados por seus avanços na compreensão dos mecanismos de ação da acupuntura, têm sido ineficazes em comprovar o que para a ciência médica moderna é o mais importante: a eficácia do uso da acupuntura no tratamento de doenças (Palmeira, 1990). O que resulta na dificuldade em ampliar a utilização da acupuntura nos sistemas nacionais de saúde, que utilizam a validação científica como parâmetro para a adoção de novos procedimentos. Esse quadro tem levado ao questionamento sobre se os métodos adotados para comprovar a eficácia da acupuntura são os mais indicados, especialmente por partir das definições científicas das doenças e padronizar sua aplicação (WHO, 2014; Contatore et al., 2015). Essa forma de proceder subverte o modo clássico singularizado de tratar por acupuntura e configura, além do descarte do conhecimento tradicional, uma sobreposição das categorias biomédicas sobre outra racionalidade de cuidado (Coutinho, Dulcetti, 2015; Ferreira, Luz, 2007; Souza, Luz, 2011). Contudo, vale assinalar que há alguns trabalhos científicos, desenhos de revisões narrativas e ensaios clínicos que valorizam o saber tradicional da medicina chinesa e se preocupam em manter a sua identidade (Aliyev, Vieth, Geiger, 2010; Dashtdar et al., 2016; Karner et al., 2013).

A utilização da acupuntura pela população mundial, conjuntamente com outras práticas "alternativas", tem crescido em maior velocidade do que a sua validação científica (Palmeira, 1990; WHO, 2014). Esse aumento tem sido relacionado a várias mudanças sociais. São procurados tratamentos mais personalizados, fugindo do modelo reducionista biomédico, que abstrai o doente e foca na doença (Luz, 2005; Moraes, 2007). Além disso, ao ser essas práticas alternativas ou complementares escolhidas por pessoas com maior poder aquisitivo e acesso aos mais sofisticados recursos que a ciência médica tem a oferecer (Giddens, 2005), subverte-se a ideia de que o científico necessariamente é melhor e de que a biomedicina é capaz de suprir as necessidades de cuidado das pessoas em geral (Palmeira, 1990; Contatore et al., 2015).

A acupuntura científica pouco ou nada tem a ver com a acupuntura tradicional chinesa, a não ser a inserção de agulhas no corpo, mas conta com grande aceitação institucional no Ocidente, pois é desenvolvida e validada dentro da racionalidade biomédica, desfrutando da legitimidade da ciência (Palmeira, 1990; Moraes, 2007; Rocha, Gallian, 2016). O aporte científico dado à acupuntura foi uma importante ferramenta para sua legitimação no Ocidente. No entanto, como aponta Palmeira (1990, p.126), considerar que o sucesso da medicina chinesa, com 2.500 anos de teorização e prática documentados, seja fruto apenas do acúmulo de observações empíricas ou reduzir o efeito da aplicação das agulhas à liberação de mediadores bioquímicos que interferem no fenômeno da dor "é fechar os olhos ao saber tradicional, é descaracterizá-lo, é optar por uma 'cegueira etnocêntrica'".

Dessa maneira, pode-se considerar que a orientação positivista e racionalista da MTC/ acupuntura, oficializada na China e difundida para o mundo, centrada em doenças ou síndromes já conhecidas e ou valorizadas pelos médicos, facilita e induz uma tripla hibridização hierarquizada e colonizada entre o conhecimento/cultura científico (colonizador) e a medicina chinesa clássica. Uma primeira hibridização deu origem à própria MTC oficial; uma segunda hibridização deu origem à acupuntura científica ou neurofuncional; e uma terceira refere-se ao fato de a acupuntura, atualmente, ser cada vez mais operada nos ambientes ocidentais, distantes do solo cultural chinês, estando sob 
muito maior influência dos modos de perceber e agir biomédicos (Palmeira, 1990; Pai, 2005; Jacques, 2005; Moraes, 2007).

Andrews (2014, p.204) observa que, "em um toque bem irônico, é precisamente esta acupuntura reformada, anteriormente considerada parte da tradição médica chinesa, que os ocidentais agora ansiosamente procuram em sua busca por alternativas e métodos mais holísticos de cura. A nova acupuntura científica é um grande negócio".

\section{Considerações finais}

O encontro entre culturas e seus saberes pode criar um espaço de acréscimo mútuo, em que os ganhos não comprometam as identidades. A hibridização entre o saber médico chinês e a medicina ocidental, idealisticamente, poderia ser um exemplo de união frutífera. Porém, como afirma Bhabha (1998), o hibridismo pode reverter o processo de recusa à assimilação de uma cultura sobre outra e fazer com que a violência do ato colonizador torne condicional o discurso colonial. Isso faz com que a autoridade colonial e suas identificações e práticas discriminatórias já não sejam imediatamente visíveis. A hibridização não faz do aspecto cultural fonte de conflito, camufla os signos de autoridade implícitos na diferenciação cultural e intervém no exercício da autoridade colonial, tornando imperceptível sua presença.

A forte influência política que permeou a mescla entre as duas medicinas ocasionou a perda do valor social da medicina chinesa. Seus preceitos foram vistos com preconceito, notadamente, pelo fato de o crescimento de atuação e a legitimação da medicina ocidental terem servido a interesses para além dos relacionados ao cuidado com a saúde, como mostrar que a China era um Estado moderno, que podia sobreviver independentemente da tutela ocidental e de estar afinada aos ideais do Estado comunista (Fruehauf, 1999; Andrews, 2014; Lei, 2014). Sua adoção, em parte, foi pela constatação de seu valor terapêutico, mas seu crescimento exponencial veio pelo poder político implícito em sua imposição, criando uma artificialidade de sua hegemonia. Incentivada e financiada por países ocidentais, a biomedicina se estabeleceu conjuntamente com a ideologia de ser a forma ideal para compreensão e tratamento dos processos de saúde e de doença (Palmeira, 1990; Moraes, 2007; Roland, Gianini, 2013).

Com isso, defendemos que, diante do contexto político da China dos séculos XIX e XX, a fundamentação da MTC não ocorreu espontaneamente por decisão unilateral do povo chinês, em um processo de mudança cultural pela absorção de outras racionalidades. Diferentemente do que postula Sean Hsiang-lin Lei (2014), não acreditamos ter sido vantajosa a estratégia de sobrevivência à modernidade, implícita nos esforços de oito décadas voltados para relacionar práticas e teorias tradicionais da medicina chinesa com a ciência moderna e a biomedicina.

A adoção de preceitos ocidentais na medicina chinesa veio com intensa perda de identidade cultural e descarte de importantes referenciais para um cuidado com a saúde abrangente e resolutivo. A hibridização resultante da ação política favoreceu o desnivelamento na atribuição de valor entre as duas medicinas, com a balança pendendo para a ocidental. Mesmo que tenha havido ganhos mútuos no decorrer do processo, não 
houve um compartilhamento equilibrado de conhecimentos entre as partes mas, sim, a assimilação do que era palatável do tradicional adaptando-o ao moderno.

Tratar da imposição de valores do colonizador ao colonizado pode ser um assunto delicado. Especialmente quando se trata de discutir os limites da racionalidade médica ocidental e considerar que há valor em outros modos exógenos de produção de conhecimento (Nascimento, 2005; Souza, Luz, 2011). Sobretudo, porque é preciso ter cuidado para não desvalorizar o desejo legítimo do povo chinês e de seus praticantes da medicina tradicional de absorver da ciência ocidental o seu leque de proposições de atenção à saúde (Luesink, 2009; Roland, Gianini, 2013; Lei, 2014). No entanto, é preciso pontuar que a desvalorização da medicina clássica chinesa, e sua posterior adaptação à lógica médico-ocidental, afetou a forma como os chineses compreenderam a melhor maneira de desenvolver sua própria medicina (Andrews, 2014).

O crescimento da influência da medicina ocidental sobre a medicina chinesa resultou no modelo utilizado nas investigações científicas que visam validar a eficácia da acupuntura. A sobreposição de valores que a ciência ocidental impõe a outros modos de produção de conhecimento (Santos, 2008) estrangula a possibilidade de haver parcerias reais de compartilhamento de saberes e cria uma falsa ideia de integração. É nessa perspectiva que Gale (2014), com muita clareza, discute a estratégia de controle implícita no mito do conhecimento científico e o quanto este favorece o domínio da biomedicina e a submissão de outras práticas a sua lógica, como vem acontecendo com a medicina chinesa. O que traz a impossibilidade sociológica de validar as medicinas complementares e alternativas, já que tal validação é baseada no modelo de produção de evidências da ciência ocidental e em noções de "verdade" cunhadas pela biomedicina.

O imperialismo na atualidade foi sutilizado no interior do plano científico, subliminarmente colocado no desejo de afirmação dos povos colonizados, que, para isso, têm como modelo o colonizador (Said, 1990; Fanon, 2008). O processo de colonização ocidental em relação aos saberes do Oriente permanece vivo pela imposição do seu modo de produzir evidências, o que proporciona uma relação de subalternidade a qualquer conhecimento que não seja produzido pelo método científico, e o seu "lugar ao sol" depende da validação por esse método. O que remete à pergunta feita por Gayatri Chakravorty Spivak (2010): "Pode o subalterno falar?"

O que é perdido pelas vozes que são caladas? No caso do distanciamento dos modos de atenção à saúde próprios da medicina clássica chinesa, pela sua cada vez maior assimilação pela biomedicina, perde-se uma estrutura caracteristicamente preventiva que produz, simultaneamente, atenção à saúde, educação para a saúde e incentivo ao autocuidado, tanto para quem a aplica como para quem a recebe. A prevenção não é obtida por uma orientação verticalizada, com a imposição do saber médico em detrimento do saber leigo; o cuidado é compartilhado e construído pela aprendizagem mútua de caminhos singularizados. Nesse sentido, a medicina clássica chinesa caminhou na mesma direção que as propostas mais atuais de cuidado à saúde (Campos, Bedrikow, 2014). Então qual é o sentido e a quem interessa a imposição de valores e métodos a que ela tem sido submetida no Ocidente?

Para Sean Hsiang-lin Lei (2014), a medicina chinesa, que no início do século XX foi considerada a antítese da modernidade, passou a ser o exemplo, no final do século, da 
criação de um tipo diferente de modernidade. Entretanto, pode-se argumentar que não há diferentes formas de modernidade, mas que são variados os tentáculos do pensamento moderno, especialmente na sua capacidade de capturar, absorver, incorporar e transformar saberes e encapsulá-los numa nova base discursiva. A constituição moderna, abordada por Bruno Latour (1994, p.51), explica tudo e esquece o que está no meio, "os híbridos, os monstros, os mistos cuja explicação ela abandona são quase tudo, compõem não apenas nossos coletivos, mas também os outros, abusivamente chamados de pré-modernos".

$\mathrm{Na}$ impossibilidade de uma única resposta a essas questões propomos uma leitura pós-colonial do tema, compreendendo que o domínio implícito no processo colonizador continua vivo pela imposição de saberes. Mesmo sabendo que a temática da hibridização da medicina clássica chinesa na conjunção com a medicina tradicional chinesa foi amplamente abordada na literatura, não se tratando, portanto, de um tema original, fica clara a necessidade de explorar outras leituras que tematizem a discussão sobre a imposição de valores culturais. Essa imposição é evidenciada na crença da ciência moderna como única forma de produzir conhecimento e no discurso que afirma a superioridade científica da acupuntura médica em relação ao conhecimento clássico da medicina chinesa.

\section{NOTAS}

\footnotetext{
${ }^{1}$ Medicina clássica chinesa refere-se ao acúmulo de conhecimento de práticas de cuidado com a saúde que, desde a dinastia Han, foi sistematizado e desenvolveu-se gradativamente até o final do século XIX, em contraposição à medicina tradicional chinesa, que se consolidou após a revolução comunista na República Popular da China, iniciada em 1949 (Barsted, 2003; Souza, 2008).

${ }^{2}$ Para mais informações a respeito da colonização ocidental na China, ver Ferro (1996) e Hobsbawn (1992).

${ }^{3}$ Nessa e nas demais citações de textos em outros idiomas, a tradução é livre.

${ }^{4} \mathrm{O}$ daoismo é um pensamento filosófico chinês (associado a várias práticas) que concebe o universo e o ser humano em movimento e mutação, numa relação intrínseca entre ser humano e natureza, sendo a base da medicina chinesa (Souza, 2008; Hemsi, 2015).
}

\section{REFERÊNCIAS}

ALIYEV, Rauf; VIETH, T.; GEIGER, Georg. Traditional Chinese medicine in diagnosis and treatment of fibromyalgia syndrome. Georgian Medical News, v.188, p.38-45. 2010.

ANDREWS, Bridie.

The making of modern Chinese medicine, 1850 -

1960. Vancouver: UBC Press. 2014.

ARRUDA, José Jobson de Andrade. Imperialismo multinacional versus colonialismo clássico. Economia e Sociedade, v.15, n.2, p.425427. 2006.

BARSTED, Dennis W.V. Linhares. $W u$ ji, o vazio primordial: a cosmologia daoista e a medicina chinesa. Tese (Doutorado em Saúde Coletiva) - Universidade do Estado do Rio de Janeiro, Rio de Janeiro. 2003.
BHABHA, Homi K.

O local da cultura. Belo Horizonte: Editora UFMG. 1998.

BIZERRIL NETO, José.

O retorno à raiz: uma linhagem taoista no Brasil. São Paulo: Attar. 2007.

BIZERRIL NETO, José.

Mestres do tao: tradição, experiência e etnografia. Horizontes Antropológicos, v.11, n.24, p.87-105. 2005.

CAMPOS, Gastão Wagner S.; BEDRIKOW, Rubens.

História da clínica e atenção básica: o desafio da ampliação. São Paulo: Hucitec. 2014.

COGGIOLA, Osvaldo.

História do capitalismo: das origens até a Primeira Guerra Mundial. O Olho da História. 
Disponível em: <http://oolhodahistoria.ufba. br/historia-do-capitalismo-e-desprestigio-dasciencias-humanas/>. Acesso em: 20 jul. 2016. 2016.

CONTATORE, Octávio Augusto et al. Uso, cuidado e política das práticas integrativas e complementares na Atenção Primária à Saúde. Ciência e Saúde Coletiva, v.20, n.10, p.3.2633.273. 2015.

COUTINHO, Bernardo Diniz; DULCETTI, Pérola Goretti Sichero.

O movimento yīn e yang na cosmologia da medicina chinesa. História, Ciências, Saúde Manguinhos, v.22, n.3, p.797-811. 2015.

DABRY DE THIERSANT, Claude Philibert. La médicine chez les chinois. Disponível em: <https://archive.org/details/

lamdecinechezle00thiegoog $>$. Acesso em: 1 jul. 2017. 1863.

DASHTDAR, Mehrab et al.

The concept of wind in traditional Chinese medicine. Journal of Pharmacopuncture, v.19, n.4, p.293-302. 2016.

FANON, Frantz.

Pele negra, máscaras brancas. Salvador: Edufba. 2008.

FERREIRA, Claudia dos Santos; LUZ, Madel Therezinha.

Shen: categoria estruturante da racionalidade médica chinesa. História, Ciências, Saúde Manguinhos, v.14, n.3, p.863-875. 2007.

FERRO, Marc.

História das colonizações: das conquistas às independências, séculos XIII a XX. São Paulo: Companhia das Letras. 1996.

FOUCAULT, Michel.

O nascimento da clínica. Rio de Janeiro: Forense Universitária. 1977.

FRÓIO, Liliana Ramalho.

A expansão da medicina tradicional chinesa: uma análise da vertente cultural das relações internacionais. Dissertação (Mestrado em Relações Internacionais) - Universidade de Brasília, Brasília. 2006.

FRUEHAUF, Heiner.

Chinese medicine in crisis: science, politics and the making of "TCM". Journal of Chinese Medicine, v.6, n.61, p.6-14. 1999.

GALE, Nicola.

The sociology of traditional, complementary and alternative medicine. Sociology Compass, v.8, n.6, p.805-822. 2014.

GIDDENS, Anthony.

Sociologia. Porto Alegre: Artmed. 2005.
GOODY, Jack.

O roubo da história. São Paulo: Contexto. 2008.

GRANET, Marcel.

O pensamento chinês. Rio de Janeiro:

Contraponto. 1997.

HALL, Stuart.

Da diáspora: identidades e mediações culturais. Belo Horizonte: Editora UFMG; Brasília: Representação da Unesco no Brasil. 2003.

HEMSI, Albert Roger.

Taijiquan: intercultura e educação. São Paulo: Virtus Educação. 2015.

HOBSBAWN, Eric J.

A era dos impérios: 1875-1914. Rio de Janeiro: Paz e Terra. 1992.

JACQUES, Lilian Moreira.

As bases científicas da medicina tradicional chinesa. São Paulo: Annablume. 2005.

JIANPING, Huang.

Metodologia da medicina tradicional chinesa. São Paulo: Roca. 2001.

JULLIEN, François.

Fundar a moral: diálogo de Mêncio com um filósofo das luzes. São Paulo: Discurso Editorial. 2001.

KARNER, Max et al.

Objectifying specific and nonspecific effects of acupuncture: a double-blinded randomised trial in osteoarthritis of the knee. EvidenceBased Complementary and Alternative Medicine, v.2013. Disponível em: <http://dx.doi. org/10.1155/2013/427265>. Acesso em: 25 ago. 2016. 2013.

LANNA, Marcos.

Sobre Marshall Sahlins e as "cosmologias do capitalismo". Mana, v.7, n.1, p.117-131. 2001.

LATOUR, Bruno.

Jamais fomos modernos: ensaio de antropologia simétrica. Rio de Janeiro: Editora 34. 1994.

LEI, Sean Hsiang-lin.

Neither donkey nor horse: medicine in the struggle over China's modernity. Chicago: University of Chicago Press. 2014.

LUESINK, David.

The history of Chinese medicine: empires, transnationalism and medicine in China, 19081937. In: Borowy, Iris (Ed.). Uneasy encounters: the politics of medicine and health in China, 1900-1937. Berlim: Peter Lang. p.149-176. 2009.

LUZ, Daniel.

Medicina tradicional chinesa, racionalidade médica. In: Luz, Madel Terezinha; Barros, Nelson Filice (Org.). Racionalidades médicas e 
práticas integrativas em saúde: estudos teóricos e empíricos. Rio de Janeiro: Uerj/IMS/Lappis. p.103-152. 2012.

LUZ, Madel Terezinha.

As instituições médicas no Brasil. Porto Alegre: Rede Unida. 2014.

LUZ, Madel Terezinha.

Novos saberes e práticas em saúde coletiva: estudo sobre as racionalidades médicas e atividades corporais. São Paulo: Hucitec. 2005.

MORAES, Maria Regina Cariello.

A reinvenção da acupuntura: estudo sobre a transplantação da acupuntura para contextos ocidentais e adoção na sociedade brasileira. Dissertação (Mestrado em Ciências da Religião) - Pontifícia Universidade Católica de São Paulo, São Paulo. 2007.

NASCIMENTO, Marilene Cabral (Org.). A duas faces da montanha: estudos sobre medicina chinesa e acupuntura. São Paulo: Hucitec. 2005.

PAI, Hong Jin.

Acupuntura: de terapia alternativa a

especialidade médica. São Paulo: Ceimec. 2005.

PALMEIRA Guido.

A acupuntura no Ocidente. Cadernos de Saúde Pública, v.6, n.2, p.117-128. 1990.

ROCHA, Sabrina Pereira; GALLIAN, Dante Marcello Claramonte.

A acupuntura no Brasil: uma concepção de desafios e lutas omitidos ou esquecidos pela história: entrevista com doutor Evaldo Martins Leite. Interface: Comunicação, Saúde, Educação, v.20, n.56, p.239-247. 2016.

ROLAND, Maria Inês de França; GIANINI, Reinaldo José.

Geraldo Horácio de Paula Souza, a China e a medicina chinesa, 1928-1943. História, Ciências, Saúde-Manguinhos, v.20, n.3, p.885-912. 2013.

SAID, Edward W.

Orientalismo: o Oriente como invenção do Ocidente. São Paulo: Companhia das Letras. 1990.

SAMPAIO, João.

História da medicina tradicional chinesa. Lisboa: [s.n.]. 2002.

SANTOS, Boaventura de Sousa. A filosofia à venda, a douta ignorância e a aposta de Pascal. Revista Crítica de Ciências Sociais, n.80, p.11-43. Disponível em: <http://rccs.revues. org/691>. Acesso em: 30 jan. 2013. 2008.

SHELTON, Tamara Venit.

Curiosity or cure? Chinese medicine and American orientalism in progressive era, California and Oregon. Oregon Historical Quarterly, v.114, n.3, p.266-291. 2013.

SOUZA, Eduardo Frederico Alexander Amaral de.

Nutrindo a vitalidade: questões contemporâneas sobre a racionalidade médica chinesa e seu desenvolvimento histórico cultural. Tese (Doutorado em Saúde Coletiva) - Universidade do Estado do Rio de Janeiro, Rio de Janeiro. 2008.

SOUZA, Eduardo Frederico Alexander Amaral de; LUZ, Madel Therezinha.

Análise crítica das diretrizes de pesquisa em medicina chinesa. História, Ciências, Saúde Manguinhos, v.18, n.1, p.155-174. 2011.

SPIVAK, Gayatri Chakravorty.

Pode o subalterno falar? Belo Horizonte: Editora UFMG. 2010.

TESSER, Charles Dalcanale.

Produção de saber, racionalidades médicas e cuidado: ideias iniciais. In: Nascimento, Marilene Cabral; Nogueira, Maria Inês (Org.). Intercâmbio solidário de saberes em saúde: racionalidades médicas e práticas integrativas e complementares. São Paulo: Hucitec. p.80-105. 2013.

TESSER, Charles Dalcanale (Org.).

Medicinas complementares: o que é necessário saber: homeopatia e medicina tradicional chinesa/acupuntura. São Paulo: Editora Unesp. 2010 .

UNSCHULD, Paul.

Medicine in China: a history of ideas. Berkeley: University of California Press. 1985.

WHO.

World Health Organisation. Tradicional medicine strategy, 2014-2023. Disponível

em: <http://apps.who.int/iris/ bitstream/10665/92455/1/9789241506090_eng. pdf?ua=1>. Acesso em: 16 mar. 2014. 2014.

WONG, Ming.

Exploração clínica na medicina chinesa: shang-han lun. São Paulo: Andrei. 1988.

\section{$\rightarrow \rightarrow \rightarrow<<<$}

